\title{
Modelling the long-term effect of climate change on a zero energy and carbon dioxide building through energy efficiency and renewables.
}

\author{
Javier M. Rey Hernández ${ }^{\mathrm{a}}$, Charles Yousif ${ }^{\mathrm{b}}$, Damien Gatt ${ }^{\mathrm{b}}$, Eloy Velasco Gómez ${ }^{\mathrm{a}}$, Julio San José ${ }^{\mathrm{a}}$ and \\ Francisco Javier Rey Martínez a \\ ${ }^{a}$ Department of Energy and Fluid Mechanics, Engineering School (EII), University of Valladolid, Spain \\ ${ }^{b}$ Institute for Sustainable Energy, University of Malta, Malta
}

\section{ARTICLE INFO}

Keywords:

ZEB Simulation,

Climate change,

Future climate

Renewable energy.

\begin{abstract}
:
Over the last few years, studies have predicted an increase in the overall air temperature due to climate change. Today's society is already sensing this change, which could have a negative impact on the environment and efforts are being made to seek all possible measures to curb it. One of the consequences of this temperature rise would be its effect on indoor comfort within buildings, which may cause higher energy consumption and operational costs, while reducing the useful lifetime of airconditioning equipment. In this paper, an existing zero energy building (ZEB) is being studied to understand the possible effects of climate change on its zero energy status. The building is also a zero carbon building because all of its generated energies come from renewable sources (biomass, geothermal and solar photovoltaic systems). The building LUCIA has the highest innovative technologies in energy systems, design and construction elements and is currently considered as one of the top three buildings with the highest LEED certification in the world. According to current
\end{abstract}

European regulations, buildings will tend to become self-sufficient in terms of energy after 2020, and therefore this study will help us to understand the changes in energy consumption within a long-term timeframe, for such zeroenergy buildings. With the aid of the DesignBuilder version 5 software and its EnergyPlus building energy engine, a building model is simulated and energy consumption is analyzed for the years 2020, 2050 and 2080 timeframe. The climatic conditions pertain to the city of Valladolid, Spain, which has a continental climate, while the expected changes in climatic conditions have been produced through the methodology developed by the University of Southampton, called CCworldweathergen.

Results have shown that the cooling demand would significantly increase for the years 2050 and 2080, while space heating would drop. This will increase the overall demand for burning more biofuels to cover the added demand in absorption cooling systems. Moreover, the previously excess generated electricity of the building by photovoltaics would then be totally consumed within the building due to increased demand. This implies that the installed systems will operate for longer hours, which will increase maintenance and replacement costs. As a result of this study, it becomes possible to quantify the expected changes in energy consumption and prepare preventive actions to anticipate this change, while improving the management and control of both the energy systems and the building. 


\section{Introduction}

The scientific evidence of climate change is quite certain, all based on the issues raised by the Intergovernmental Panel on Climate Change (IPCC) and as suggested by the American Environmental Protection Agency (EPA), which both refer to the evidence of climate change [1].

Climate change is defined as a stable and durable change in the distribution of weather patterns over periods of time. It could be a change in average weather conditions or the distribution of events around that average. Climate change may be limited to a specific region, or can cover the entire earth's surface $[1,2]$.

In order to mitigate this change and its impacts, emissions of greenhouse gases should have peaked in 2015 and progressively decreased thereafter up to $50 \%$ by 2050 [3]. However, the progressive evolution of atmospheric $\mathrm{CO}_{2}$, has been observed to actually increase and has recently reached an unprecedented high of 400 parts per million ( $\mathrm{ppm}$ ). This development has prompted scientists to make processes to predict future climate in different cities, for the purpose of designing buildings and optimising their thermal comfort in the coming years, without loading the ecosystem with further environmental degradation [4,5]. Consequently greater efficiency of HVAC equipment, and better designs for the building envelope are constantly being developed to achieve various parameters of comfort and improve the overall satisfaction levels of users, while consuming less energy [6,7]. It is to be noted that buildings account for a significant amount of energy consumption which reaches $40 \%$ in the EU $[8,9]$.

This paper investigates the effect of weather due to climate change on the energy performance of a zero energy building (ZEB), situated in the city of Valladolid, Spain. Simulation using DesignBuilder version 5 software and running on the EnergyPlus Building Model engine has been carried out for different weather climates for 2020, 2050 and 2080. The final outcome would give answers to frequently asked questions on whether today's building techniques are sufficiently resilient to keep the indoor climate of buildings comfortable and what added measures need to be made to maintain comfort [10]. In this way, one can anticipate any changes and counter balance their effects through energy efficiency and better design, thus saving energy [11].

The building model used for this case study is a real building that was designed to be near zero energy building and also zero $\mathrm{CO}_{2}$ through the use of renewable energies. The building forms part of the Campus of the University of Valladolid and serves as a real life laboratory for the application of innovative energy and renewable energy systems.

Monitoring of actual consumption is on-going. The collected data was used to calibrate the simulation model using a meteorological weather file for Valladolid for 2016. The calibration adjustment of this model is made by working with typical days and not extreme days. The energy flows as reported in the model's results and the real values were compared. The trend of results showed a discrepancy of between 0 and 3\% [12]. Following that, more simulation were made for future weather climates for 2020, 2050 and 2080, using the renowned DesingBuilder version 5 with EnergyPlus version 8.5.0.001 building energy simulation engine [13]. In this way, one can anticipate any changes in energy profiles and counterbalance their effects through energy efficiency and better design, thus saving energy [14].

The quantitative variation of the data parameters within a weather file due to climate change will have a direct impact on the energy consumption of a ZEB. Despite working on a Zero Energy building, one would still expect a real change in energy demand [15]. It is predicted that the energy consumption will increase over time because temperatures tend to increase due to climate change, projecting a prolonged use of air conditioning for cooling and reducing the demand for heating [16]. The focus on space conditioning stems from the fact that more than $50 \%$ of the building's energy consumption is due to space conditioning [17].

\section{Methodology}


At the beginning, the Meteonorm software weather database was checked for the study of future climate. Meteonorm is a distinct database that was developed over the years by a private company, which is different from the one developed by the University of Southampton, UK, which belongs to public entities.

At first glance, Meteonorm is designed with more complete climate data than other databases. Although, the base historic data is obtained from actual meteorological stations, it uses a spatial interpolation method to generate the database, in case there are no data for certain sites. Therefore, such database could be useful for sites that do not have access to real historic weather data [18].

In our case, there was full access to weather data of Valladolid using the database framed within the CTE 2013 Spanish standard for buildings [19]. The reason for using this file is the need to simulate buildings with typical meteorological local weather files that offer stability without significant variations between different years, thus creating a representative climatic balance to the model over the weather climate of the past ten years. The use of a typical meteorological year weather file will therefore allow us to focus on comfort measures and the possibility of doing a much more detailed study, excluding atypical values in weather conditions [20]. Due to the minimal variation caused between the parameters of the 2016 meteorological local year weather used in the calibration and the typical meteorological local year weather used in the simulation, the existing discrepancies have been accepted [12].

The University of Southampton, UK has developed a simulator for climate change of meteorological files (CCworldweathergen) for the years 2020, 2050 and 2080, by which variation of meteorological parameters are modelled to obtain climate forecasts. Such future weather files can then be implemented in simulation programmes, to calculate the energy performance of different buildings, and optimise the design to achieve better energy control throughout the years [21,22].

For the purpose of this paper, we begin by describing the file generator (CCWorldWeatherGen), which gives us the opportunity to create new future weather files based on archived data for virtually all existing locations. The first step is to convert the weather file of Valladolid from Energy Plus Weather (EPW) format to an MS Excel data file. This can be made by using the "Data File and Statistics Utility" freely available from EnergyPlus website [7]. The data file can then be used with a climate change model of the University of Southampton, which is working on a methodology called 'morphing' for processing changes of meteorological data, as developed by Belcher, Hacker and Powell [23]. The tool (CCWorldWeatherGen) allows us to generate time series climate change files very fast. Moreover it is public and freely available $[16,17]$. Once this algorithm was implemented in the climate data file, three new weather data files were generated besides the original data file, namely the typical meteorological file and weather files for the years 2020, 2050 and 2080.

Following the above steps, attention is turned to the energy use simulation software, which is a computer program that performs a time series calculation of the energy behaviour of a virtual building in a transient regime, known as dynamic simulation (where the different parameters vary over time). With this type of simulation, many parameters are taken into consideration including the heat capacity of the building envelope, usually known as the inertia of the building, heat flow, solar gains, ventilation and other parameters. The combined analysis of all these factors is run by the software several times every hour. Thus, it is possible to study in detail the evolution of any specific parameter throughout the year, such as the relative humidity or the temperature or the heating and cooling load of a selected zone.

The work process involves building the model in 3D and inputting all the physical parameters pertaining to the building envelope, mode of operation, heating and cooling systems, ventilation, water heating, and lighting, besides others. A climate file that defines the weather of the locality of interest is also added. The calculation engine uses all this data to make an annual simulation of the thermal and energy performance behaviour of the building. Simple programmes, such as energy certification programs that are commonly used in Spain, give general annual data on energy consumption. However, more complex programmes are also used to give hourly results of all outputs, which may include energy demand, indoor temperatures, and humidity, surface temperatures, comfort levels and other results [26,27].

DesignBuilder v.5, with its inbuilt EnergyPlus dynamic simulation programme used in this paper is wellknown worldwide and offers a powerful tool to perform energy simulations. EnergyPlus is one of the most recognized and widely used tools for analysing multi-zone systems. It is a thermal and energy 
simulation programme of buildings that has been developed and updated over decades by the Department of Energy of the United States of America.

The building's 3D-model is shown in Figure 1. The model was provided in AutoCAD format by the Technical Architecture Unit (UTA) of the University of Valladolid and this model could be introduced into DesignBuilder easily.

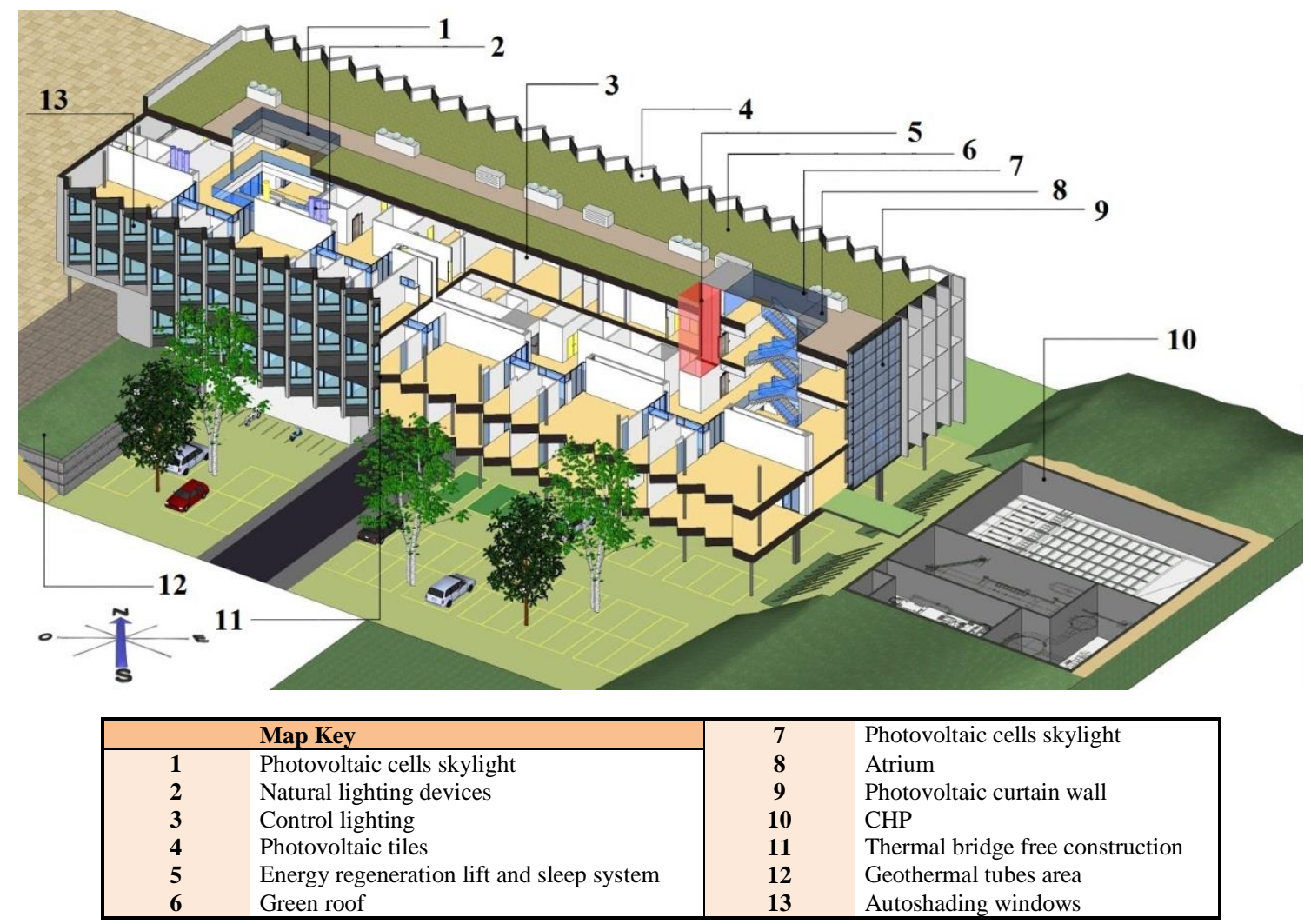

Fig. 1. Artist impression of the 3D ZEB LUCIA

Quality checks were also carried out to ensure that the provided model and the actual building characteristics match. The development of the model is not only proposed at a structural level, but also as an energy model. Figure 2 shows the modeled building in Design Builder platform.

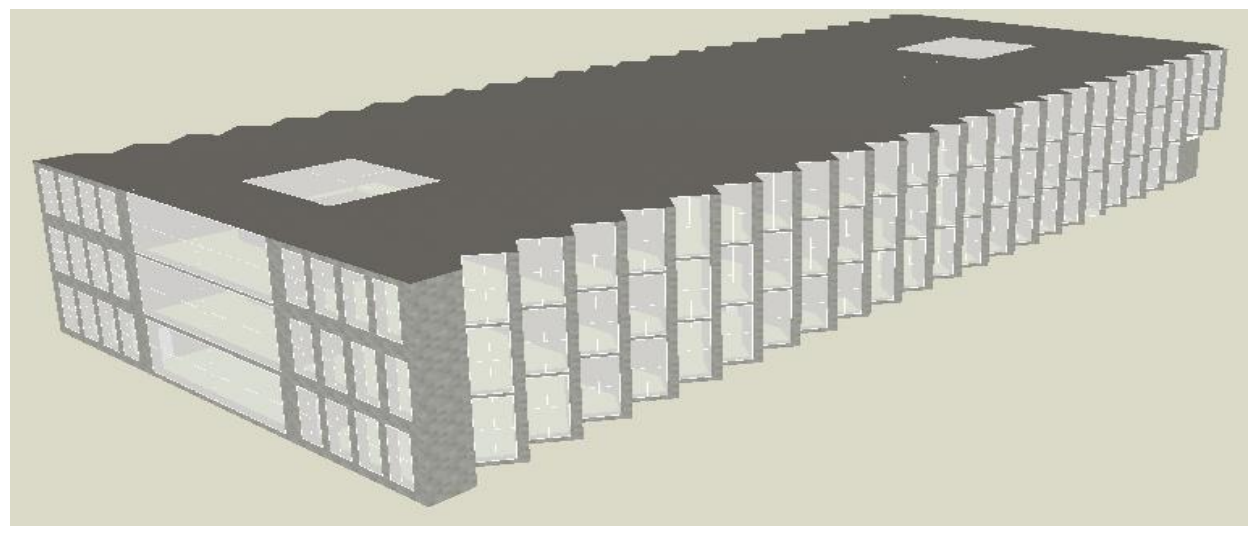

Fig. 2. Model of the LUCIA building by Design Builder 


\section{Description of the case study ZEB Building with zero $\mathrm{CO}_{2}$ emissions.}

The "LUCIA" zero-energy zero-carbon building is situated at the University of Valladolid, in the city of Valladolid, Spain [12]. The specific building has a total area of 7,500 $\mathrm{m}^{2}$, and it belongs to the certified category of zero energy buildings, mainly composed of laboratory, research and spin-off spaces related to metabolopathies $\left(2.100 \mathrm{~m}^{2}\right)$; nutrition, food and diet $\left(2.100 \mathrm{~m}^{2}\right)$ and development of the knowledge digital society $\left(950 \mathrm{~m}^{2}\right)$ (Figure 3$)$.

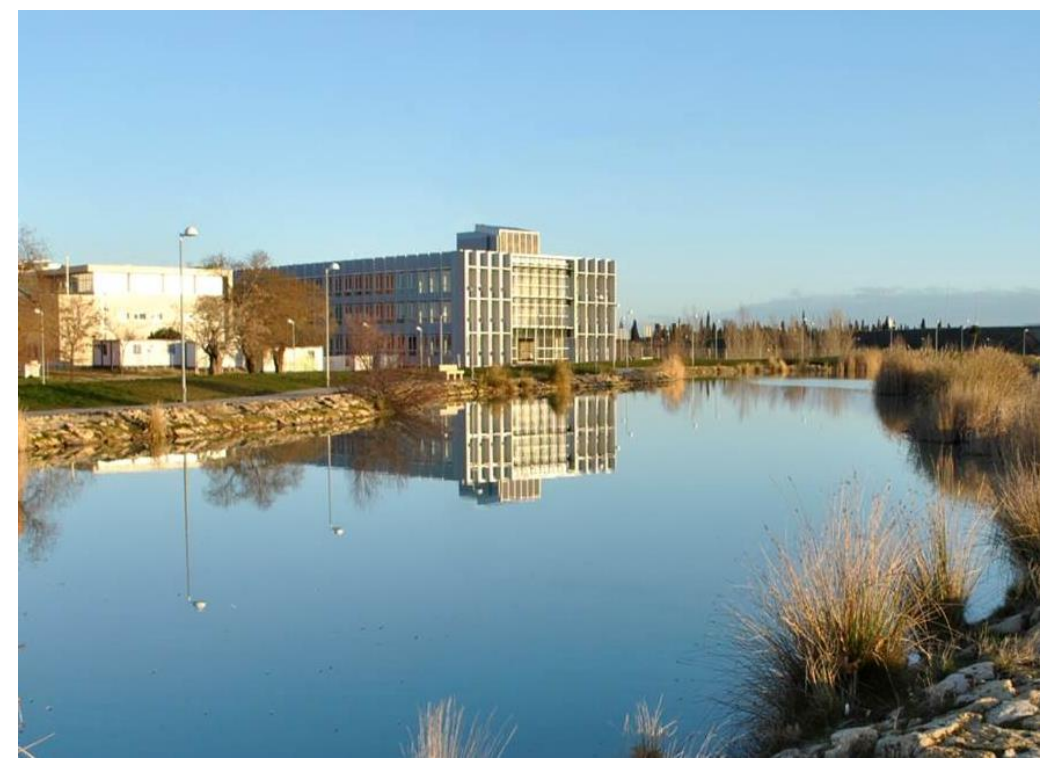

Fig. 3. LUCIA building, Valladolid, Spain

LUCIA is considered as one of the flagship reference ZEB buildings in the world, with the highest possible accreditations certified with 98 points in LEED certification. This is the maximum score attained so far in Europe and in the whole Northern hemisphere for any building, and the second highest rating of LEED PLATINUM in the whole world, only surpassed by the building PIXEL in Australia [28].

On the other hand, this ZEB is also certified by another tool, the Green Tool (Green Building Council Spain - GBC Spain), which evaluates the environmental impact of the building according to 12 indicators of the Basic Set of Indicators (CSI) of the European Environmental Agency (EEA), with the priorities set in the European and national policies and with the Agency's management plan [29,30]. These are subject to regular review and linked with other international indicators. The result of 4.52 out of 5 indicates the high environmental quality of the building.

This Zero Energy Building reduces 31\% the depletion of non-renewable resources, when compared to the primary energy of standard buildings, and more than $90 \%$ of the impacts of buildings over climate change, loss of soil fertility and the emission of photo-oxidizers products. It also reduced almost by $100 \%$, the damage that the building could make on aquatic life or the production of hazardous waste [12].

The building is being fully monitored by energy meters for the boiler, the cogeneration plant, the chiller, the absorption unit and the hot water for sanitary use systems (power, flow rates, stored energy) always through ModBus protocol; heating, ventilation and air conditioning energy consumption is also being monitored through pulse counters. There are also over 97 electrical network analyzers distributed all around the building to measure the zone's active energy, reactive energy, phase voltage, frequency, 
through ModBus protocol [31]. It is therefore possible to monitor the levels of energy consumption and comfort for each zone.

The building also introduces simple solutions for architectural integration of photovoltaic solar energy, which favour the objective of neutral emission of $\mathrm{CO}_{2}$ (Fig. 4 and Fig. 5). The European Directive 2010/31/EU urges Member States to ensure that all newly constructed buildings are nearly zero energy buildings (NZEB) as of December $31^{\text {st }} 2020$, while public administration buildings, need to comply two years earlier in January 2019, to lead by example. The Spanish Order FOM/1635/2013 of September $10^{\text {th }}$, updates BD HE and transposes Directive 2010/31/EU of the European Parliament and of the Council of 19 May 2010 on the energy performance of buildings. The order establishes a first step to the objective of Nearly Zero Energy buildings, within Spanish building regulation [19].

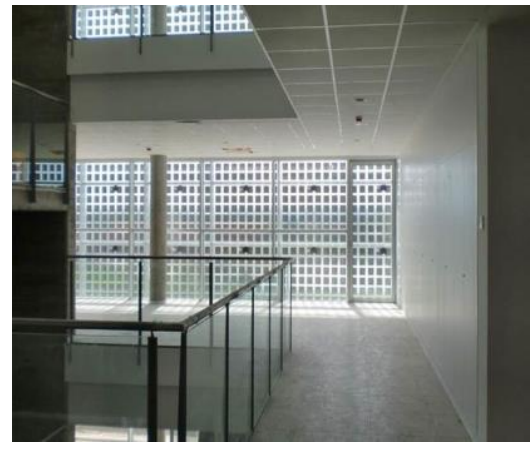

Fig. 4. Internal view of PV modules on facade

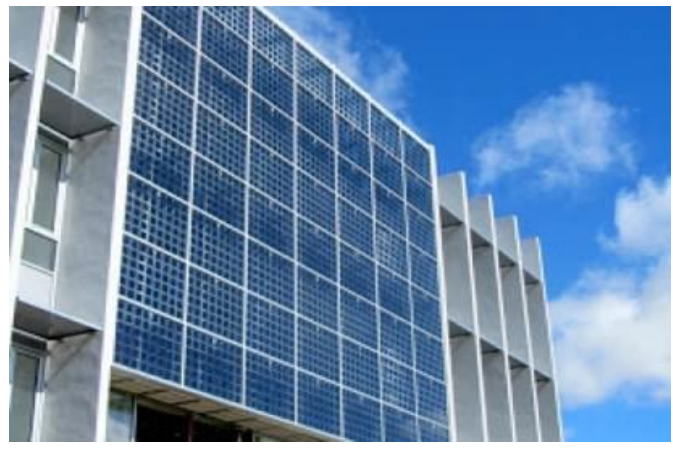

Fig. 5. External view of the PV modules on facade

This building also incorporates passive measures for a south bioclimatic building design, such as orientation, enhancement of solar gains in winter and sun control in summer, as well as natural ventilation with geothermal recovery, thermal insulation of walls and apertures and double glazed argon-filled windows.

Combined heat and power systems fueled by biomass, together with high efficiency heating, ventilation and air-conditioning systems, coupled with back-up absorption cooling system and geothermal systems have all been installed. Natural lighting has been introduced as an important concept in this development, both for direct and diffuse radiation, through the use of special devices. Artificial lighting is controlled through the use of high efficiency lights together with lux level intensity and occupancy control. This building also sets new levels for saving water, through collection and reuse of rainwater and grey water, with separation networks in the laboratories that allow treatment prior to discharge; sanitary appliances have been equipped with electronic taps with reduced water flow. The use of native vegetation on the roof that does not need irrigation system has also been considered.

Bioclimatic building design, increased insulation, passive ventilation and other strategies and technology measures allow the reduction in energy demand by more than $50 \%$, when compared to a standard building simulated as the base scenario building in DesignBuilder, For lighting, savings of $45 \%$ were achieved, mainly due to the large glazed façade covering $46 \%$ of the total wall area, coupled with the special introduction of hollows, overhead lighting devices such as light tubes and regulation of the lux level according to the external luminosity. The use of renewable energy systems, especially the CHP plant provides $30 \%$ extra energy generated, which supplements the energy needs of the annex nearby buildings. The overall result is Zero energy and balance zero in carbon $\left(\mathrm{CO}_{2}\right)$ emissions for this building.

Another important element of the design has been the use of materials of low environmental impact and life cycle, having minimum production energy and low emission certificates for their manufacture. Recycled materials and re-used building elements, which reduce as much as possible the waste generated in the construction process, while being easily removable, have been extensively used (Figure 6). 


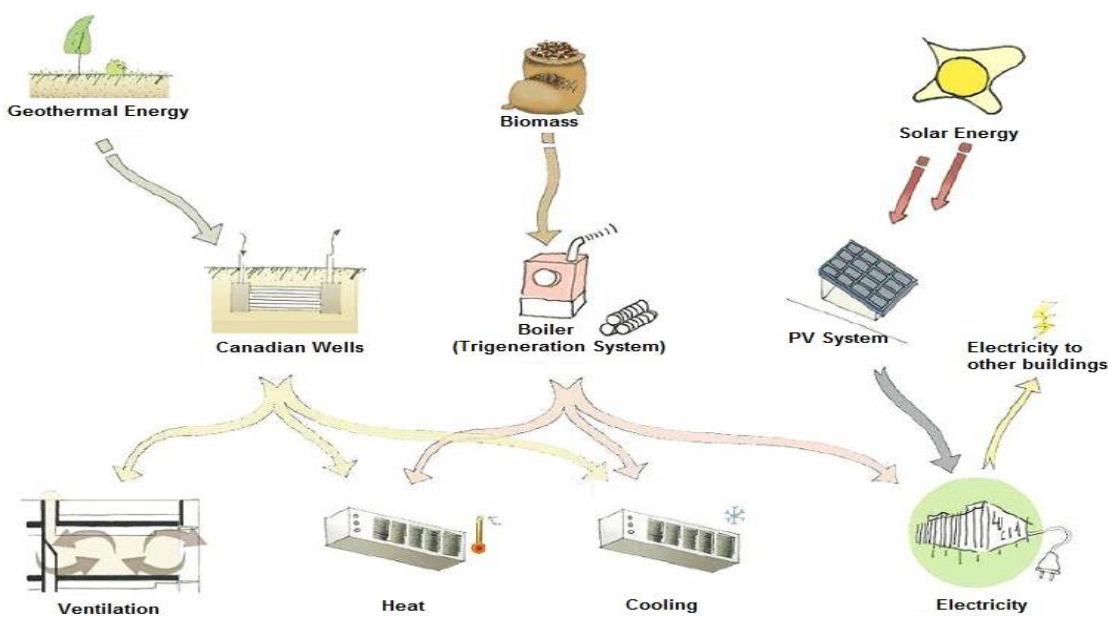

Fig. 6. Renewable energy generation systems used in the building

The main construction characteristic of this building is the zigzag shaped facade, which generates an auto-shading and a natural eave due to the forged concrete on the top of each window and glass surface, for both east and west orientations. The building was built with plastered internal insulated walls with a thermal transmittance of $0.157 \mathrm{~W} / \mathrm{m}^{2} \mathrm{~K}$, and a high thermal inertia, which reduces the impact of the external temperature changes on the building. In addition, the photovoltaic facade of the building produces a similar shadow to the one produced by double envelope systems. One also notes the use of green roofs to reduce the urban-heat-island effect on the surface.

The combined heat and power system of the building, fuelled by biomass, has a consumption (of biomass) between $100-125 \mathrm{~kg} / \mathrm{h}$. This generates electricity to the value of $100-130 \mathrm{kWh}$ and a thermal energy production of $200-220 \mathrm{kWh}$, of which $100-110 \mathrm{kWh}$ is supplied at $90{ }^{\circ} \mathrm{C}$ and the remaining 100 $110 \mathrm{kWh}$ at $450{ }^{\circ} \mathrm{C}$. Additionally, there are two conventional biomass boilers to produce heat as a backup, only when the heating demand of the building exceeds $200 \mathrm{~kW}$ (Figure 7).

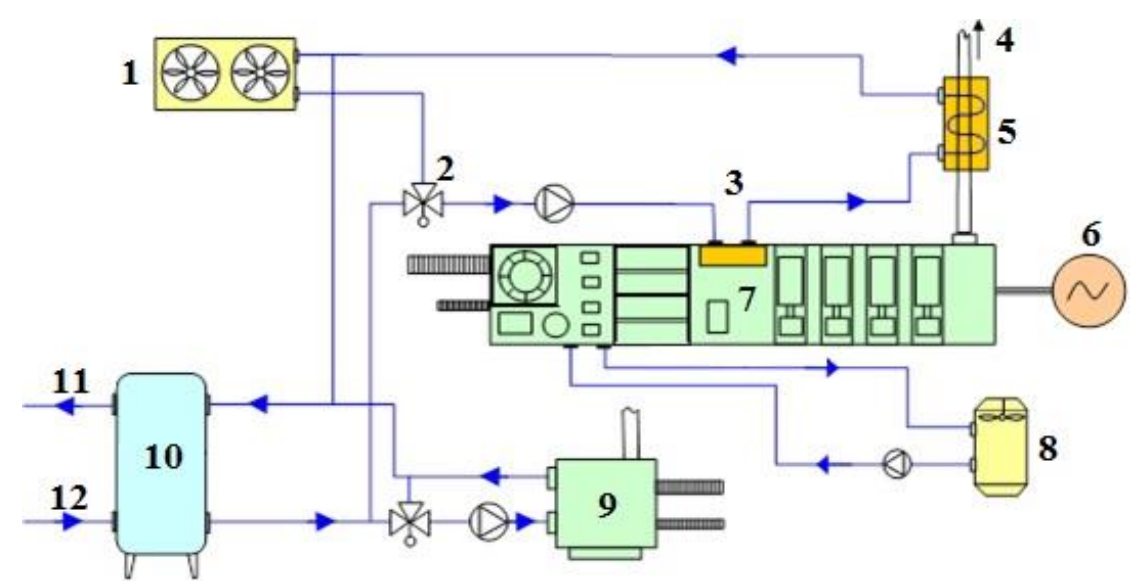

\begin{tabular}{|c|c|c|c|}
\hline \multicolumn{4}{|c|}{ Map Key } \\
\hline 1 & Cooling (Air-Water) $200 \mathrm{~kW}$ & 7 & CHP (Biomass) \\
\hline 2 & Control Valve & 8 & Cooling tower \\
\hline 3 & Engine cooling & 9 & Biomass Boiler 300kW \\
\hline 4 & Exhaust gases CHP & 10 & Thermal storage \\
\hline 5 & Energy Recovery 90kW & 11 & Hot water Discharge $90^{\circ} \mathrm{C}$ \\
\hline 6 & Electricity supply & 12 & Hot water Return \\
\hline
\end{tabular}

Fig. 7. CHP system 
This heating system is connected to a biomass cogeneration system, as part of a gasification process for biomass, where the electricity is produced through the controlled burning of biomass. This generates gas that is introduced in several internal alternative rectified combustion engines to generate electricity, as shown in Figure 8.

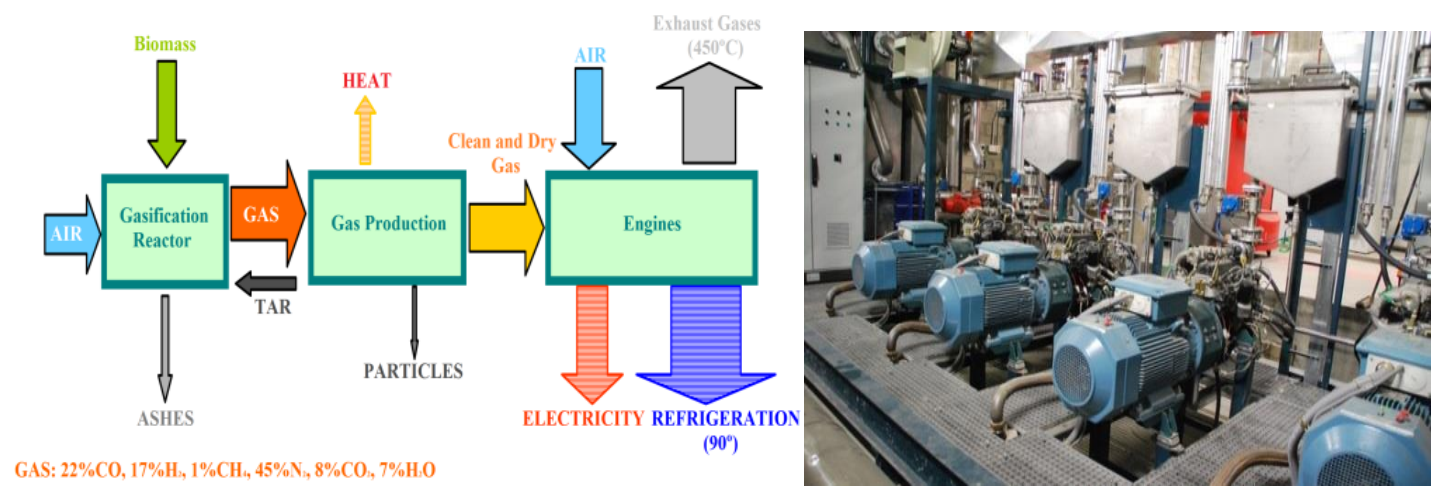

Fig. 8. Biomass Cogeneration

The CHP system works in an uninterrupted way and at maximum power from 8 a.m. to 10 p.m. from Monday to Friday. This is carried out by 5 engines with 4 of them producing 100-130 kW, while the fifth one is permanently kept in reserve mode, to allow for maintenance operations and emergency situations.

This building works with heat recovery units, reaching a $61 \%$ recovery rate; the remaining percentage is generated by a biomass boiler using wood chips, a common fuel in the region where the building is situated, given the extensive forest landscape. This CHP boiler has a nominal power rating of $329 \mathrm{~kW}$ and an efficiency of 0.88 .

The air-conditioning system of the building comprises a 100\% external constant flow system that supplies heating and cooling associated to the ventilation system (Figure 9). The heat is managed by 4-tube fancoil systems distributed throughout the building.

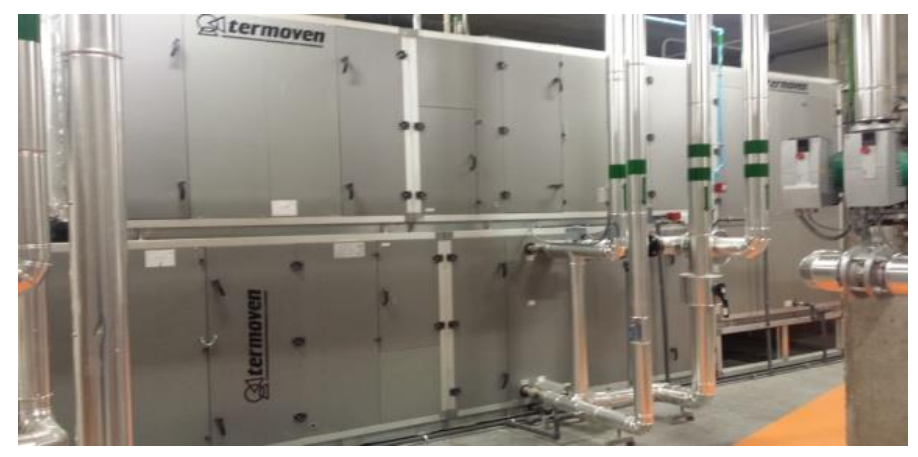

Fig. 9. Air Handling Unit System with indirect evaporative recovery (AHU)

An absorption cycle provides cooling to the building with energy efficiency ratio (EER) of 0.7 and a power of $176 \mathrm{~kW}$ (Figure 10). In addition, it possesses a conventional air cooling system with a capacity of

$232.7 \mathrm{~kW}$ and an EER of 3.3 (Figure 11). A cooling tower with two fan speed serves to remove the waste heat produced by the absorption system. The flow of the fans and external air ventilation system reach $15,000 \mathrm{~m}^{3} / \mathrm{h}$. The model of control of air-conditioning of this building can be done in two different ways, first through the control of the constant airflow, and second through the set temperature, depending on the season. 


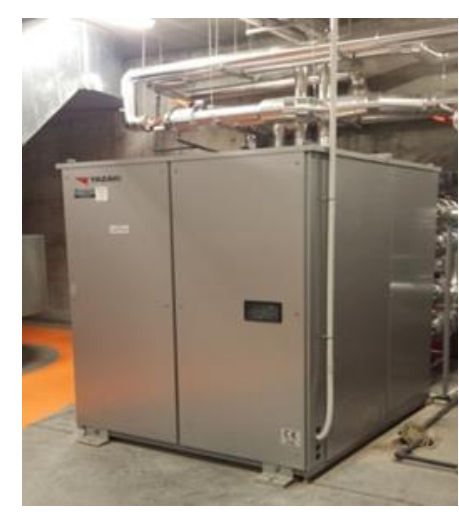

Fig. 10. Absorption Cooling System

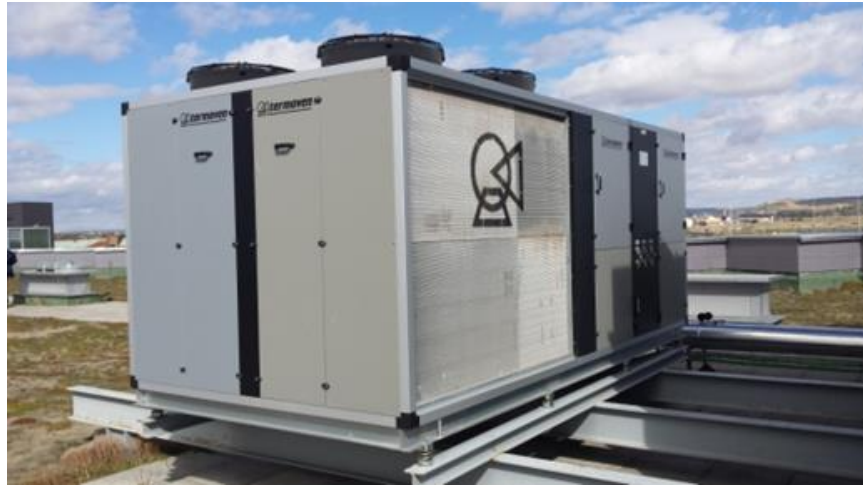

Fig. 11. Chiller system

It is possible to use free-cooling in the main air treatment unit when the system is generating cool air in summer, which increases the efficiency of the systems. This is carried out by a geothermal ventilation system of Ground Heat Exchanger (GHE) and a nocturnal ventilation system, in order to cool the building in a natural way. The ventilation system of the building presents four working modes, with GHE, without GHE and additionally there is the possibility of working with or without free cooling (Fig.12). Also there is the possibility of adding the heat recovery option. In summary the modes could be: with GHE and heat recovery, without GHE and heat recovery, or only free cooling, where neither the GHE nor the heat recovery systems are working. The control system implemented in the energy systems aims to reach the set points through the cheapest energy system due to an enthalpy control, taking into account the consumption of the auxiliary elements involved in the use of the different technologies.

The GHE system is comprised of 56 wells, of $200 \mathrm{~mm}$ diameter and 16 metres buried pipes, with an estimated flow of $15,000 \mathrm{~m}^{3} / \mathrm{h}$. This provides a heating close to $162,000 \mathrm{kWh} /$ year and a cooling supply of $150,740 \mathrm{kWh} /$ year, for the 6,264 working hours of the building per year. When analysing the $\mathrm{CO}_{2}$ emissions saving, this translates to $13,380 \mathrm{~kg}$ for free heating mode and 7,650 kg for free cooling mode of $\mathrm{CO}_{2}$ saved per year.

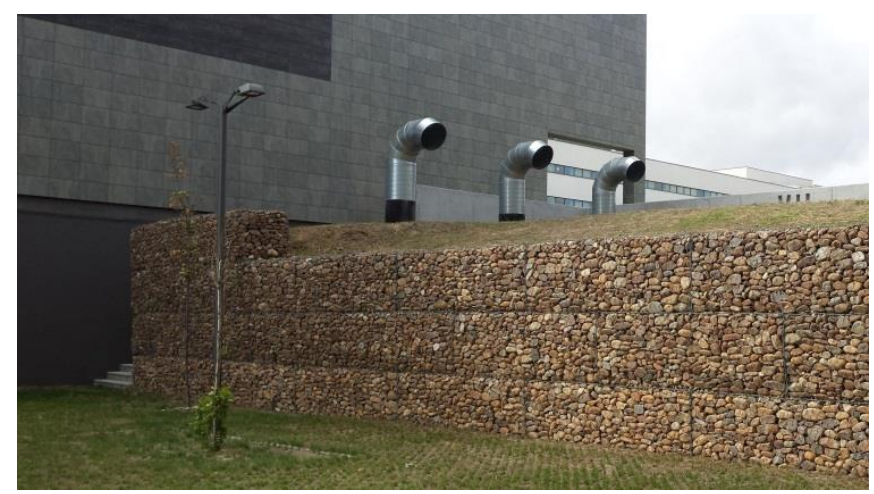

Fig. 12. GHE

The lighting of the building includes electronic T5 ballasts with Digital Addressable Lighting Interface, (DALI), built in the suspended ceiling, and is designed according to lighting regulations. This aims to supply offices and laboratories with $9.7 \mathrm{~W} / \mathrm{m}^{2}$ and corridors with $3.8 \mathrm{~W} / \mathrm{m}^{2}$. In circulation and other areas, downlight LEDs and DALI fluorescents are used [32].

All these implemented measures of energy efficiency demonstrate the effectiveness of bioclimatic building design strategies employed in the building, in order to extrapolate these strategies to other 
constructions. The savings achieved from each independent measure also aim to ensure the total traceability of the energy production of the building itself and the intake of biofuel, in order to confirm the $\mathrm{CO}_{2}$ zero emissions status and estimate the surplus energy produced, or alternatively, the import energy needed to satisfy the demand. Figure 13 shows the flow diagram of the energy processes in the building.

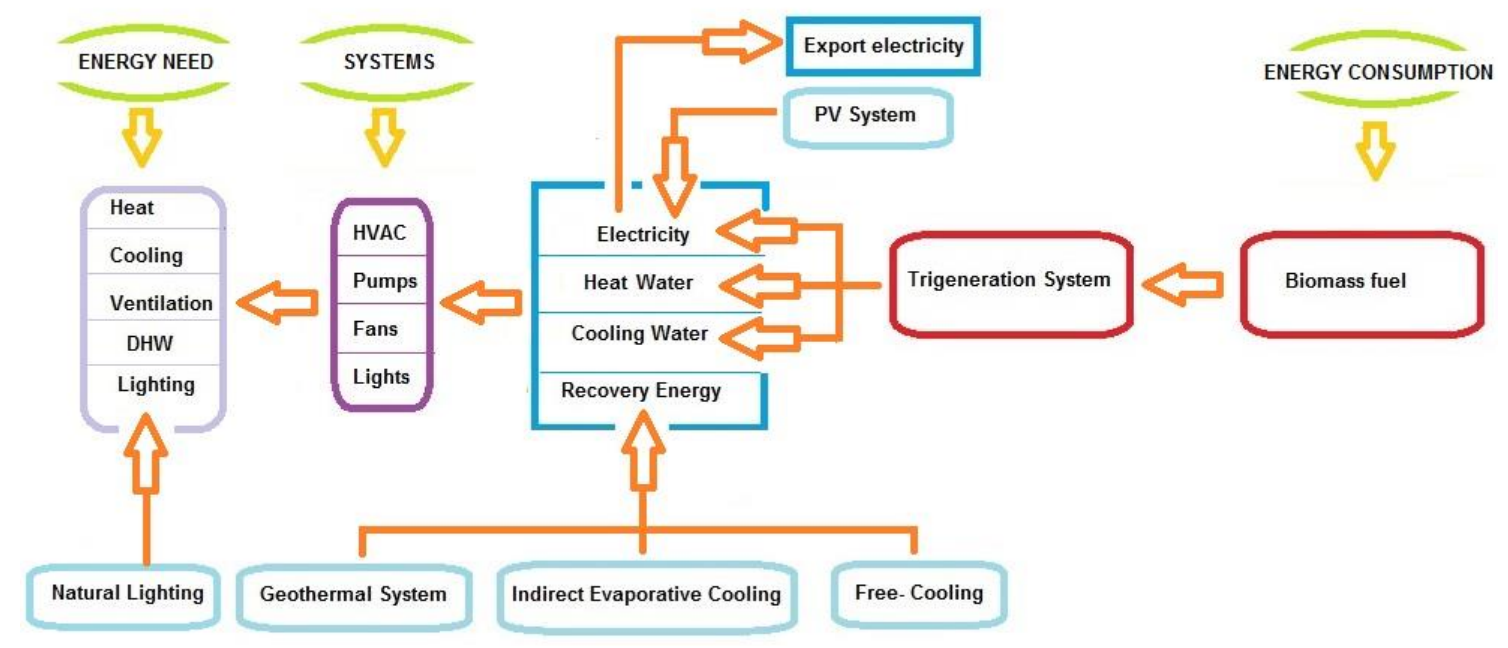

Fig. 13. Energy Systems flow chart of the ZEB

The building is controlled by an advanced control and management integrated system called DESIGO ${ }^{\mathrm{TM}}$, created by SIEMENS and based on the SCADA technology (Supervisory Control and Data Acquisition software) [33]. This DESIGO system is designed to guarantee optimal management of all the installations, including HVAC, electrics, fire control, intrusion, alarms, registration, etc. It generates a predictive control of the building, which allows to anticipate the different errors that may occur.

Figure 14 shows one of the screens of the HVAC control through SCADA, where it is shown all the parameters to be controlled, such as temperatures, enthalpies, humidity, pressure, energy, consumption of fans and energy systems, filter status, carbon emissions, and it is also shown that there is the possibility of controlling everything both manually and automatically.

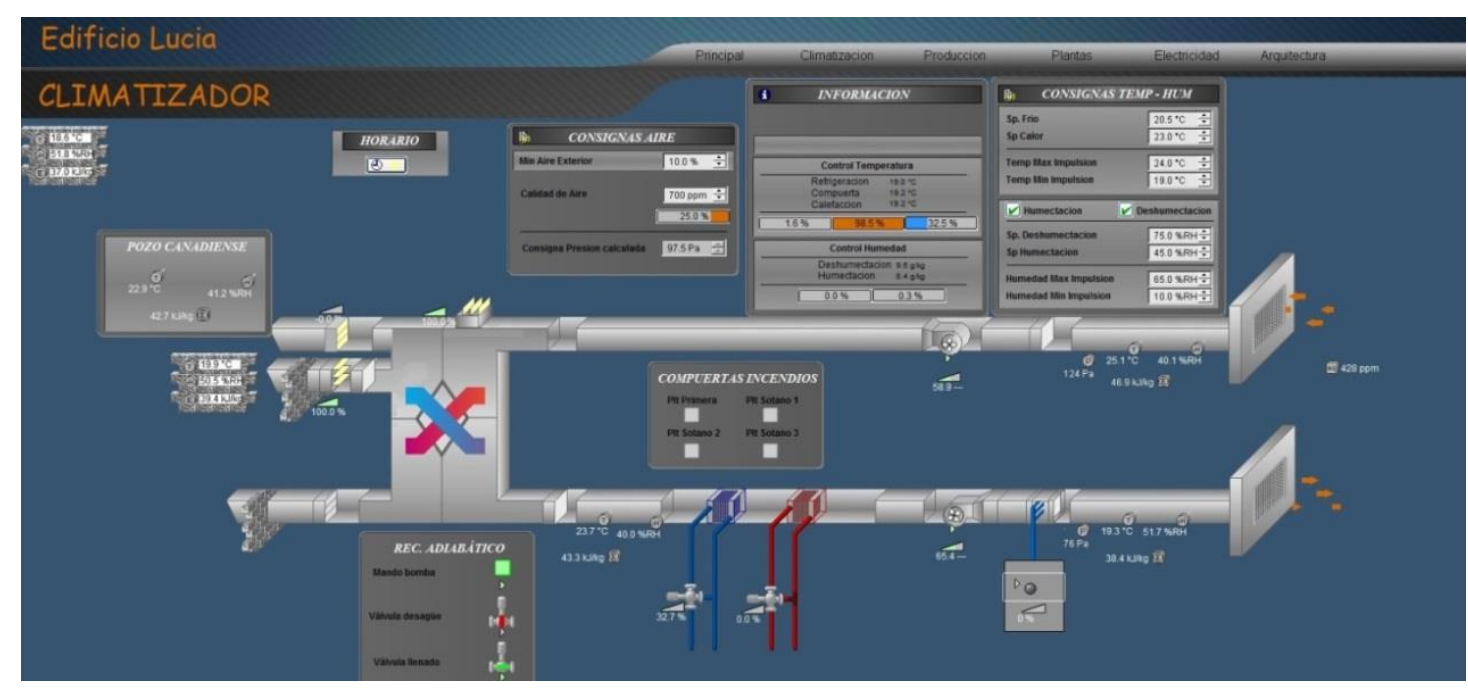

Fig. 14. Screenshot of DESIGO, air handling unit (SCADA Siemens) 
The main characteristic of the system is the ability to perform an integrated management of the energy processes of the building, ensuring that the supplied energy at every moment is as low as possible. To this effect, DESIGO works by integrally monitoring all the sensors, hardware, measuring and regulation of instruments of the building. It registers and stores all the information collected in the time frame established by the user (Fig 15).

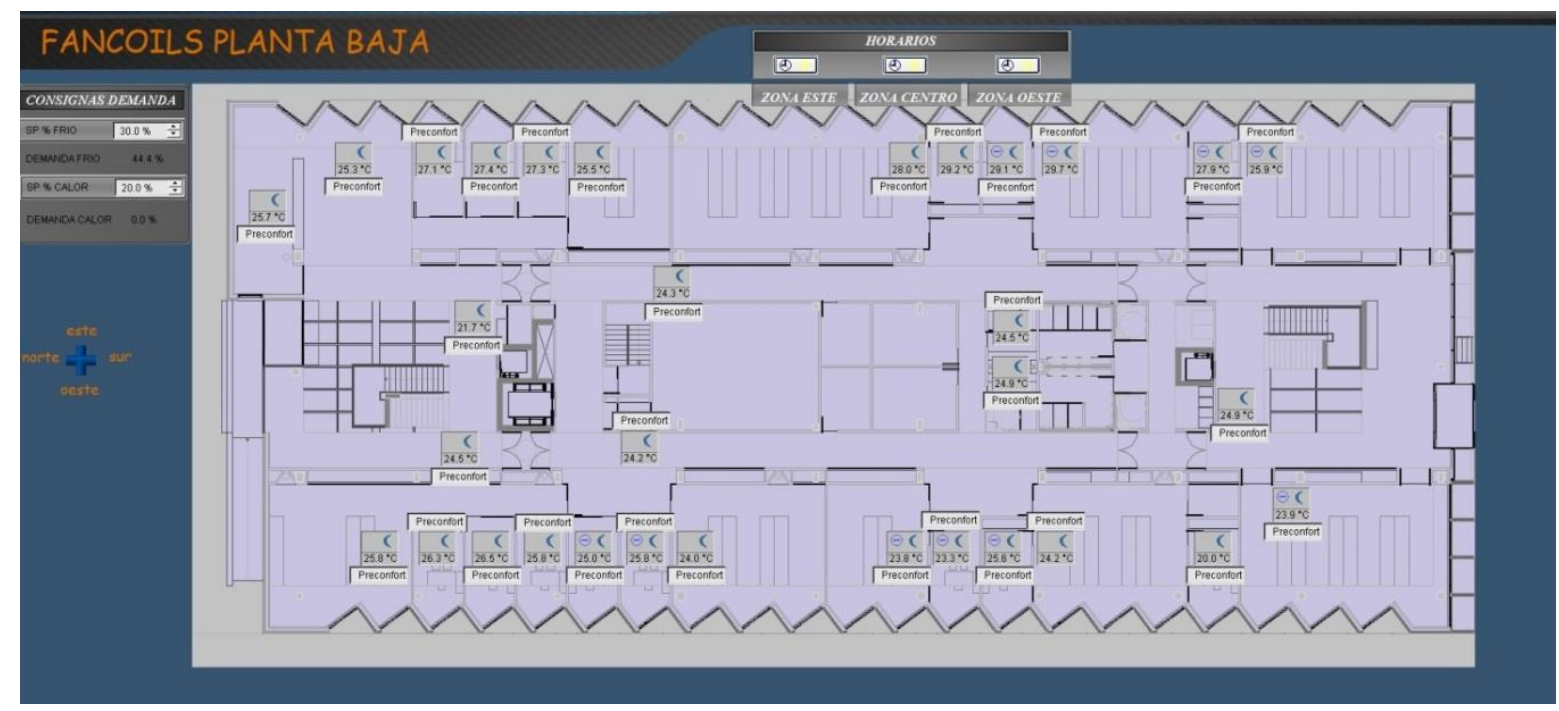

Fig. 15. Screenshot of DESIGO, operative temperature control for lower floor (SCADA Siemens)

Each one of the consumption parameters are accounted and registered periodically by the central control and monitoring system of the building. The system stores the data and regularly generates reports for the analysis of consumption.

The replacement of energy systems at the end of their service life will require, at least, the maintenance of the current installed power capacity. However, improvements in the technology used will be accepted, which may lead to lower replacement costs.

Finally, a building with these characteristics makes a perfect experimental unit for the testing and analysis of new measures of energy efficiency or changes in the working parameters of existing actions, to bring about a step change in designing and building future constructions that will be carbon neutral and also stand the test of time with regards to climate change effects on indoor comfort.

\section{Results and Data Analysis}

After the model has been validated, DesignBuilder was run to simulate the building's energy performance behaviour. Table 1 below shows the breakdown of the building's energy consumption, divided into heating, cooling, hot water and lighting, as well as the generation of energy by the biomass tri-generation system and photovoltaic system. The separation of consumption in flow, discharge and return, is due to the mode of operation of the building, which is always over-pressured to reduce dirt and pollution ingress. The discharge flow of the HVAC System refers to all the consumption associated with the discharge, such as the consumption of fans, pumps, etc. The same occurs to the return flow of the HVAC System, which includes all the consumption associated with the return. It is to be noted that the tri-generation system produces heating, cooling as well as electricity.

Taking the 2020 energy performance of the building as a benchmark, it is possible to compare the 2050 and 2080 scenarios to it, with a breakdown of energy consumption and generation as shown in Table 1 below.

Lighting consumption was seen to slightly increase by $0.5 \%$ to $1 \%$ by 2080 . This can hardly be considered as a change, as it is within the error margin of the forecasting of the weather file. Hence, one 
can assume that lighting demand will not change by 2080 and would therefore need no further analysis. Moreover, the lighting energy consumption has the least energy share of the whole energy demand of the building, as shown in Figure 16.

Table. 1. Energy Consumption of the ZEB LUCIA in 2020, 2050 and 2080.

\begin{tabular}{|c|l|cc|cc|cc|}
\cline { 3 - 8 } \multicolumn{1}{c|}{} & \multicolumn{2}{|c|}{$\mathbf{2 0 2 0}$} & \multicolumn{2}{c|}{$\mathbf{2 0 5 0}$} & \multicolumn{2}{c|}{$\mathbf{2 0 8 0}$} \\
\hline \multirow{5}{*}{ Consumption } & Chiller & 88 & $M W h$ & 114 & $M W h$ & 158 & $M W h$ \\
& Absorption & 34.2 & $M W h$ & 44.3 & $M W h$ & 61.3 & $M W h$ \\
& Discharge Flow HVAC System & 62.3 & $M W h$ & 80.7 & $M W h$ & 112 & $M W h$ \\
& Return Flow HVAC System & 55.1 & $M W h$ & 71.4 & $M W h$ & 98.8 & $M W h$ \\
\cline { 2 - 9 } & Heat & 146 & $M W h$ & 122 & $M W h$ & 94.2 & $M W h$ \\
& Domestic Hot Water & 7.2 & $M W h$ & 6 & $M W h$ & 4.7 & $M W h$ \\
& Absorption Heat & 27.1 & $M W h$ & 22.6 & $M W h$ & 17.4 & $M W h$ \\
\cline { 2 - 9 } & Lighting & 78.1 & $M W h$ & 78.4 & $M W h$ & 79.9 & $M W h$ \\
\hline \multirow{5}{*}{ Generation } & 22.3 & $M W h$ & 22.3 & $M W h$ & 22.4 & $M W h$ \\
& PV System & 476 & $M W h$ & 517 & $M W h$ & 603 & $M W h$ \\
\hline
\end{tabular}

On the other hand, space heating (including domestic water heating) and space cooling, which accounted for $36 \%$ and $48 \%$ of the total energy demand in 2020, respectively, underwent major changes. As the weather regime becomes warmer through 2050 to 2080, lower heating and higher cooling loads have been perceived. This will shift the percentage contribution of sectoral energy consumption, as shown in Figure 16. By 2080, heating would represent only $18 \%$ of energy consumption compared to $69 \%$ for cooling and $13 \%$ for lighting. This prompts us to appreciate that measures for alleviating the effect of climate change would have to focus primarily on reducing the cooling load.

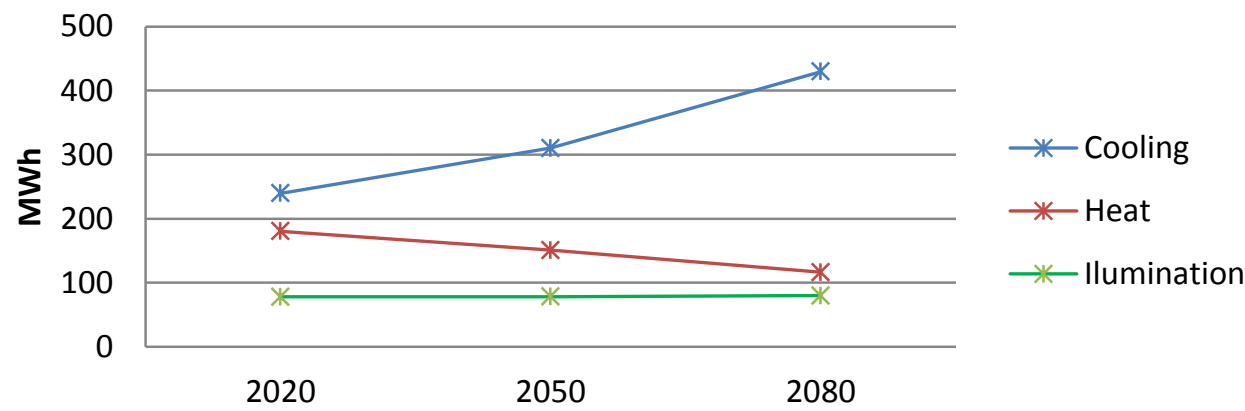

2020

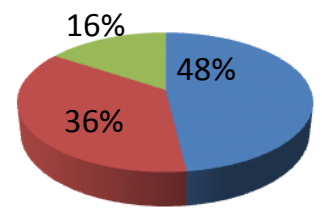

2050

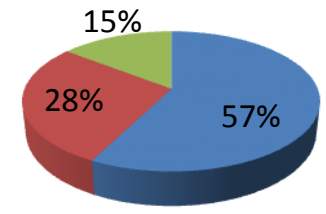

2080

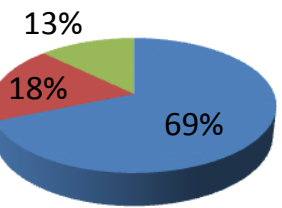


Fig. 16. Sectoral energy consumption, Cooling, Heat and Illumination of LUCIA ZEB for different future climates, 2020,2050 and 2080

The electric energy that feeds LUCIA building is produced by two autonomous systems, namely photovoltaic and cogeneration systems, which were previously described. This building is designed to work mostly on electrical energy produced from cogeneration, with the possibility of exporting any extra energy to nearby buildings or to the electricity grid. In this analysis it can be seen that $88 \%$ of the electrical generation of the building is covered by the tri-generation system, compared to $12 \%$ being produced from the solar photovoltaic modules placed on the walls and part of the roof of the building (Figure 17). The photovoltaic system on the roof is installed on top of the two stairwells shown in Figure 1 , as a skylight.

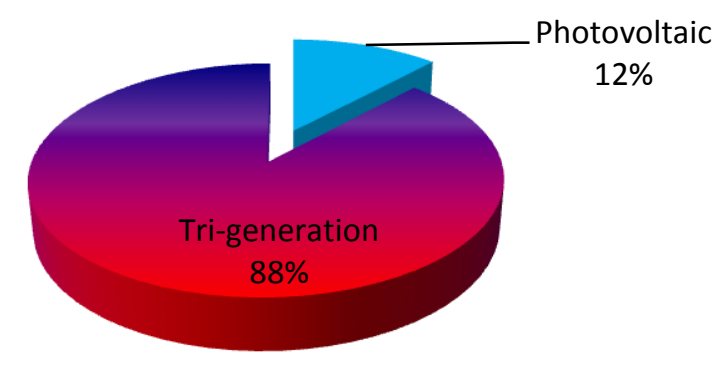

Fig. 17. On-site electricity generation by Photovoltaic and Tri-generation

Focusing closer on the energy analysis for heating and cooling only, it is seen that the percentage contribution of heating would drop to $21 \%$, while cooling demand will form $79 \%$ of total air-conditioning demand by 2080, as shown in Figure 18. However, it is important to note that cooling is generated by the tri-generation system and photovoltaic panels, which provide electrical energy to power the chiller, while for heat generation (winter time), it is exclusively focused on tri-generation based on the burning of biomass.

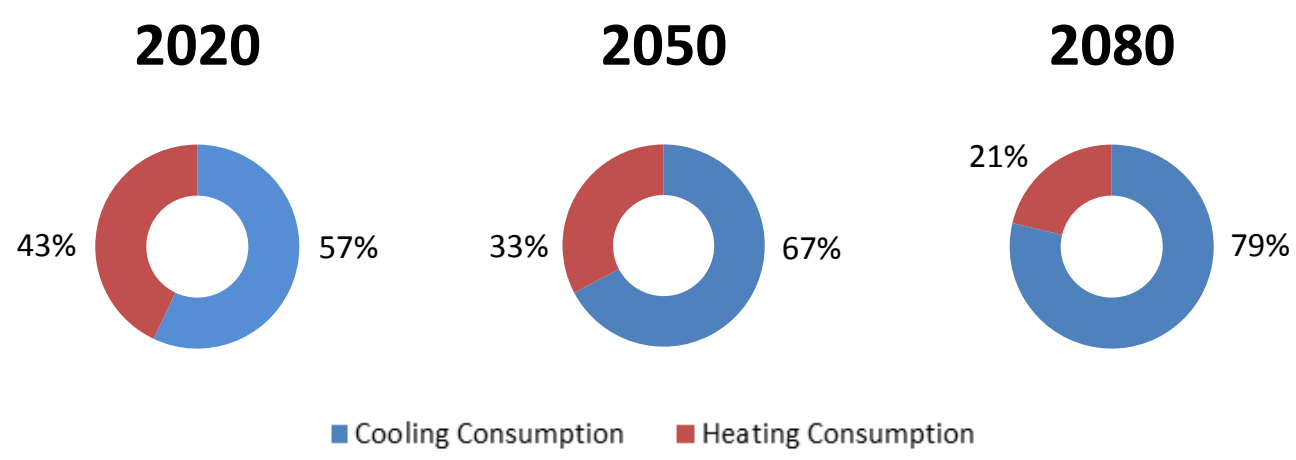

Fig. 18. Heating-Cooling percentage energy consumption share for different future years

The heat generated by burning biomass, is utilized in three areas; the first one is to supply domestic hot water (DHW), which requires $4 \%$ of total heating consumption. This building does not have large hot water demand, given that it is mostly used for office-based and laboratory activities. The second heating demand share of $15 \%$ is used in the absorption cooling system, mostly during summer, while the remaining $81 \%$ is used for intrinsic heating of the building (Figure 19). 


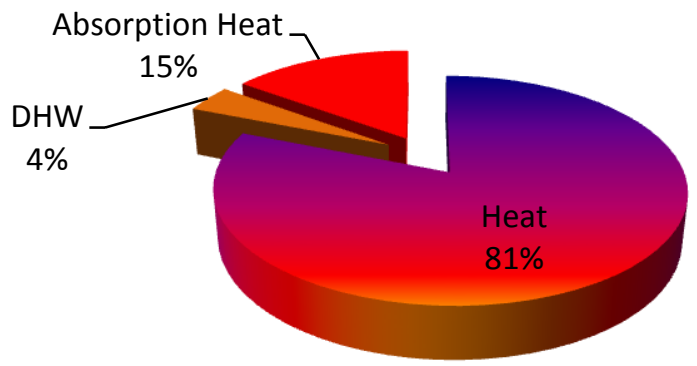

Fig. 19. Distribution of biomass heat generation

As can be seen, almost all the heat generated by the tri-generation system is directed towards heating the building. This percentage would drop by time since the need for heating will decrease. Therefore, most of the thermal energy will now be utilized by the absorption units to cool the building rather than heating it.

With regards to space cooling, the distribution of energy consumption for the different cooling systems is that $37 \%$ is consumed by the chiller, while the absorption system accounts for $14 \%$ of the total energy consumed for cooling. The remaining $49 \%$ of energy consumption for cooling is almost equally divided between the discharge flow and return flow HVAC system, which includes energy consumption for all fans, pumps, and the air handling unit (AHU). The small difference in energy consumption between discharge and return is justified by the building's overpressure, where infiltration is kept to a minimum (Figure 20).

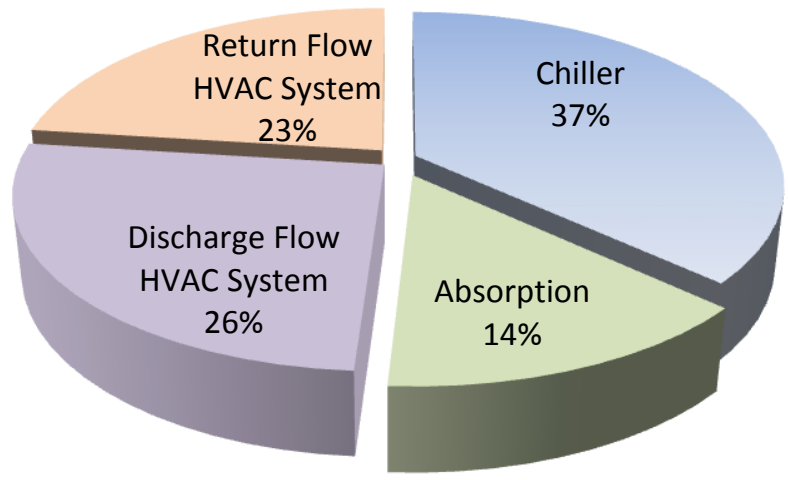

Fig. 20. Cooling energy consumption. Half of this consumption is by the energy systems, Chiller and Absorption, the remain is by the HVAC distribution system

When simulating the weather climate changes for the years 2050 and 2080, it was demonstrated that the cooling load will increase. Figure 21 shows the cooling systems' energy consumption (kWh) versus the year for the LUCIA ZEB building. This trend is the same for all the systems. 


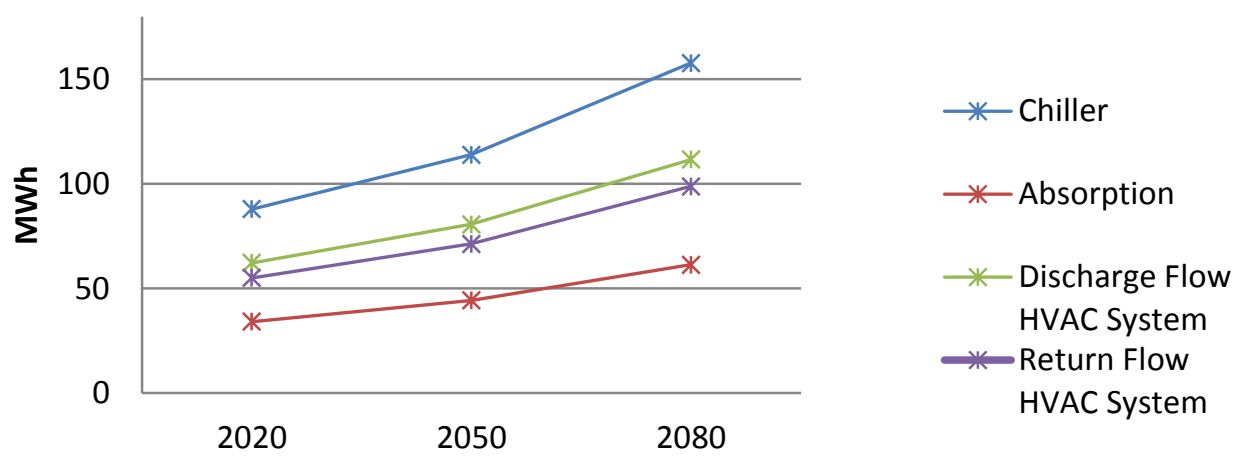

Fig. 21. Cooling energy consumption for different future years climate scenarios

According to the Spanish Standard for buildings, the design of energy systems in buildings is carried out outside peak demand, since the total energy demand of the building to be covered is at the $95 \%$ confidence level, in accordance with regulations and the peak loads forming a very small part of the total energy demand fall within the remaining $5 \%$.

Nevertheless, focusing on an exhaustive study of peak demand, the energy systems which supply energy to the building perfectly satisfy the entire peak and total demand for 2020 and 2050. On the other hand, while the peak energy demand for heating in 2080 is also fully satisfied, the cooling demand is not full covered for a few hours. However, this does not represent a considerable problem, because these hours are below the remaining 5\% confidence level and therefore the design satisfies the Spanish regulations.

The weather simulation report has shown that the external air temperature between 2020 and 2050 is expected to increase by almost $1.5^{\circ} \mathrm{C}$ in winter and by $3{ }^{\circ} \mathrm{C}$ in summer. This trend will continue for the period 2050 to 2080 , with an additional $1.1{ }^{\circ} \mathrm{C}$ increase on average, which corresponds to an increase of $11.67 \%$ in temperature compared to 2020. Figure 22 shows the development of the external temperatures versus the months for different future years. Clearly, the effect is that more cooling and less heating will be needed for the control of temperature within the building.

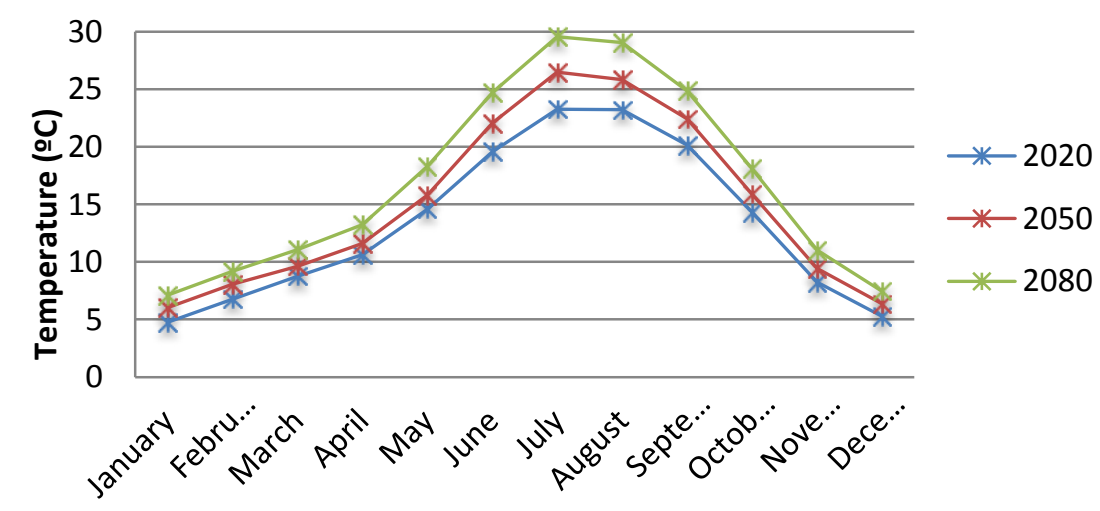

Fig. 22. Simulated evolution of external air temperatures for future years in 2020, 2050 and 2080.

When comparing these changes of ambient temperatures with the comfort limits as set in the ISO 7730 standard for peak and minimum temperatures, one could summarize the effects as shown in Table 2, where the maximum and minimum temperatures are a seasonally average temperature [34]. 
Table 2. Increase of peak and minimum temperatures by intervals of years.

\begin{tabular}{|c|c|c|c|c|c|c|}
\hline Intervals & \multicolumn{2}{|c|}{$2020 \rightarrow 2050$} & \multicolumn{2}{|c|}{$2050 \rightarrow 2080$} & \multicolumn{2}{|c|}{$2020 \rightarrow 2080$} \\
\hline $\begin{array}{l}\text { External } \\
\text { Temperature }\end{array}$ & $\begin{array}{l}\left(4.7^{\circ} \mathrm{C} \rightarrow 6.0^{\circ} \mathrm{C}\right) \\
\left(23.3^{\circ} \mathrm{C} \rightarrow 26.5^{\circ} \mathrm{C}\right)\end{array}$ & $\begin{array}{l}\text { Winter } \\
\text { Summer }\end{array}$ & $\begin{array}{l}\left(6.0^{\circ} \mathrm{C} \rightarrow 7.1^{\circ} \mathrm{C}\right) \\
\left(26.5^{\circ} \mathrm{C} \rightarrow 29.5^{\circ} \mathrm{C}\right)\end{array}$ & $\begin{array}{l}\text { Winter } \\
\text { Summer }\end{array}$ & $\begin{array}{l}\left(4.7^{\circ} \mathrm{C} \rightarrow 7.1^{\circ} \mathrm{C}\right) \\
\left(23.3^{\circ} \mathrm{C} \rightarrow 29.5^{\circ} \mathrm{C}\right)\end{array}$ & $\begin{array}{l}\text { Winter } \\
\text { Summer }\end{array}$ \\
\hline $\begin{array}{l}\text { Indoor Air } \\
\text { Temperature }\end{array}$ & $\begin{array}{l}\left(18.6^{\circ} \mathrm{C} \rightarrow 18.8^{\circ} \mathrm{C}\right) \\
\left(25.8^{\circ} \mathrm{C} \rightarrow 26.5^{\circ} \mathrm{C}\right)\end{array}$ & $\begin{array}{l}\text { Winter } \\
\text { Summer }\end{array}$ & $\begin{array}{l}\left(18.8^{\circ} \mathrm{C} \rightarrow 19.4^{\circ} \mathrm{C}\right) \\
\left(26.5^{\circ} \mathrm{C} \rightarrow 27.0^{\circ} \mathrm{C}\right)\end{array}$ & $\begin{array}{l}\text { Winter } \\
\text { Summer }\end{array}$ & $\begin{array}{l}\left(18.6^{\circ} \mathrm{C} \rightarrow 19.4^{\circ} \mathrm{C}\right) \\
\left(25.8^{\circ} \mathrm{C} \rightarrow 27.6^{\circ} \mathrm{C}\right)\end{array}$ & $\begin{array}{l}\text { Winter } \\
\text { Summer }\end{array}$ \\
\hline $\begin{array}{l}\text { Indoor Radiant } \\
\text { Temperature }\end{array}$ & $\begin{array}{l}\left(18.5^{\circ} \mathrm{C} \rightarrow 18.7^{\circ} \mathrm{C}\right) \\
\left(27.6^{\circ} \mathrm{C} \rightarrow 28.3^{\circ} \mathrm{C}\right)\end{array}$ & $\begin{array}{l}\text { Winter } \\
\text { Summer }\end{array}$ & $\begin{array}{l}\left(18.7^{\circ} \mathrm{C} \rightarrow 19.4^{\circ} \mathrm{C}\right) \\
\left(28.3^{\circ} \mathrm{C} \rightarrow 29.0^{\circ} \mathrm{C}\right)\end{array}$ & $\begin{array}{l}\text { Winter } \\
\text { Summer }\end{array}$ & $\begin{array}{l}\left(18.5^{\circ} \mathrm{C} \rightarrow 19.4^{\circ} \mathrm{C}\right) \\
\left(27.6^{\circ} \mathrm{C} \rightarrow 29.0^{\circ} \mathrm{C}\right)\end{array}$ & $\begin{array}{l}\text { Winter } \\
\text { Summer }\end{array}$ \\
\hline $\begin{array}{l}\text { Operative } \\
\text { Temperature }\end{array}$ & $\begin{array}{l}\left(18.5^{\circ} \mathrm{C} \rightarrow 18.8^{\circ} \mathrm{C}\right) \\
\left(26.7^{\circ} \mathrm{C} \rightarrow 27.4^{\circ} \mathrm{C}\right)\end{array}$ & $\begin{array}{l}\text { Winter } \\
\text { Summer }\end{array}$ & $\begin{array}{l}\left(18.8^{\circ} \mathrm{C} \rightarrow 19.4^{\circ} \mathrm{C}\right) \\
\left(27.4^{\circ} \mathrm{C} \rightarrow 28.0^{\circ} \mathrm{C}\right)\end{array}$ & $\begin{array}{l}\text { Winter } \\
\text { Summer }\end{array}$ & $\begin{array}{l}\left(18.5^{\circ} \mathrm{C} \rightarrow 19.4^{\circ} \mathrm{C}\right) \\
\left(26.7^{\circ} \mathrm{C} \rightarrow 28.0^{\circ} \mathrm{C}\right)\end{array}$ & $\begin{array}{l}\text { Winter } \\
\text { Summer }\end{array}$ \\
\hline
\end{tabular}

This increase in external air temperature implies a variation in the comfort parameters, and therefore, when establishing the indoor air control temperatures, preventive adjustments will have to be made to counter balance this quantitative increase of temperature inside the building. In the first 30 years, from 2020 to 2050, indoor air will be affected by an increase of less than $1{ }^{\circ} \mathrm{C}$ for the operative temperature $\left(0.3{ }^{\circ} \mathrm{C}\right.$ in winter and $0.7^{\circ} \mathrm{C}$ in summer. For the years between 2050 and 2080 , the increase in indoor air temperature is of the order of another $0.7^{\circ} \mathrm{C}$.

When comparing these temperatures to the requirements of the Standard CTE Framework of Spain for buildings, which sets the winter temperature to $21{ }^{\circ} \mathrm{C}$ and the summer temperature to $26{ }^{\circ} \mathrm{C}$, it becomes apparent that an added cooling load will be required in summer and less heating in winter.

Figure 23 shows the development of the operative temperatures to control versus the months for different intervals of years. It can be seen that the operative temperature increases from 2020 to 2080 and the difference is more pronounced between June and September. The evolution of temperatures is always rising up to a maximum $28^{\circ} \mathrm{C}$ in summer and this needs to be controlled.

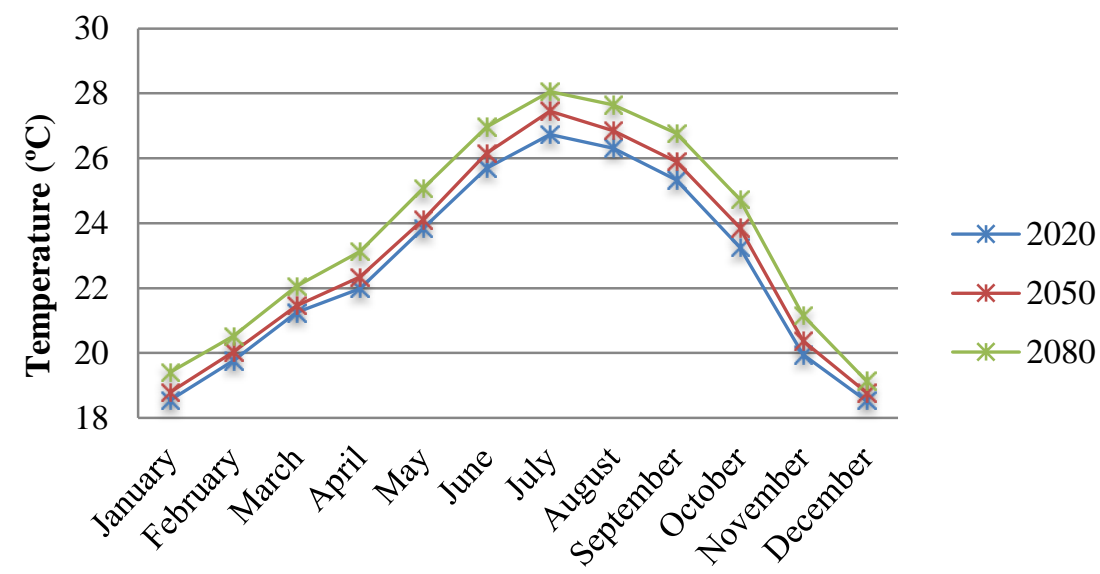

Fig. 23. Development of the operative temperature over the years versus the months in 2020, 2050 and 2080

It is worth noting that the increase in indoor temperature due to climate change is not only a result of external temperature rise but also due to more solar gains. Over the coming future years between 2020 and 2080, an increase between 4 and $6 \%$ in solar gain is expected. In addition, it is important to mention that the heat losses through the walls will be lower, given that the temperature gradient between indoor and external air is lower. The drop in heat losses is on the order of $8 \%$. 
To summarize, the overall effect of weather changes on the heating and cooling demand is shown in Table 3. One notices that as the years progress, the hybrid heating-cooling periods in the lee months mostly disappear and are replaced by cooling only.

Table 3. Increase of consumption by intervals of years.

\begin{tabular}{|l|c|c|c|}
\hline \multicolumn{1}{|c|}{ Intervals } & $\mathbf{2 0 2 0} \rightarrow \mathbf{2 0 5 0}$ & $\mathbf{2 0 5 0} \rightarrow \mathbf{2 0 8 0}$ & $\mathbf{2 0 2 0} \rightarrow \mathbf{2 0 8 0}$ \\
\hline Total Heating Consumption & $-11.98 \%$ & $-18.56 \%$ & $-28.32 \%$ \\
\hline Total Cooling Consumption & $+16.44 \%$ & $+21.85 \%$ & $+34.00 \%$ \\
\hline
\end{tabular}

Monthly heating demand is shown in Figure 24 for the different years under study. It can be seen that the heating demand between May and October is practically nil and therefore any heating generated by the tri-generation system shall be devoted to the production of cooling by the absorption system.

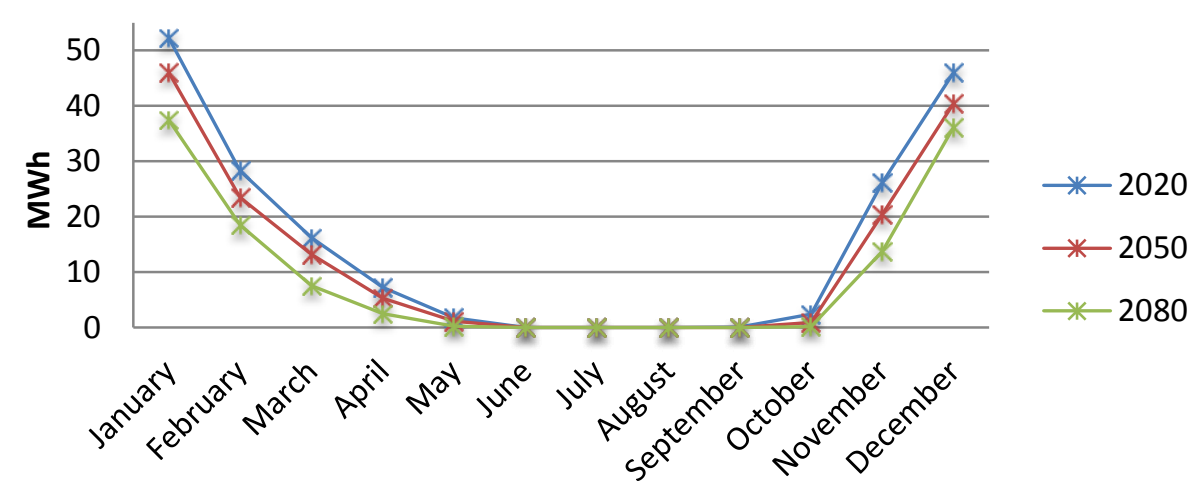

Fig. 24. Monthly total demand for space heating along the years 2020, 2050 and 2080

With regards to cooling, the demand is expected to increase by $34 \%$ by 2080 . This will be mainly covered by the tri-generation system that burns biofuel to supply energy to the absorption system. The contribution of solar photovoltaics is expected to remain constant for the whole period, because although the solar radiation is expected to increase slightly (therefore higher generation of solar photovoltaic electricity), but the external temperature will also increase (causing lower efficiency of the photovoltaic panels), thus making the net effect on photovoltaic electrical production minimal.

Figure 25 shows the monthly changes in cooling energy consumption for the years 2020, 2050 and 2080. It is worth noting that certain months such as May and October that had little demand for cooling will eventually require much more. 


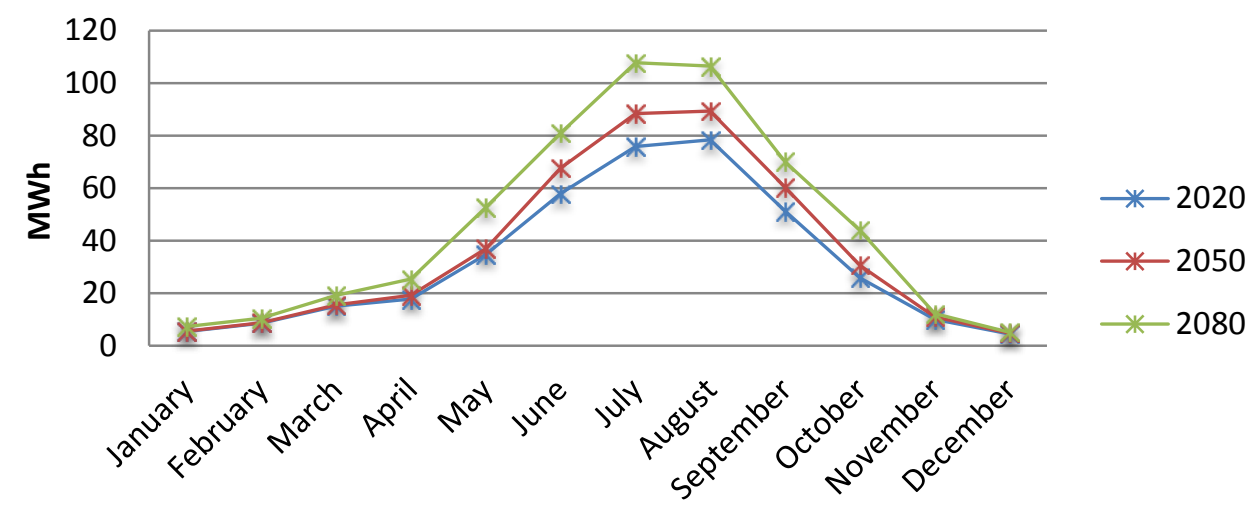

Fig. 25. Total Cooling consumption versus months for different years, 2020, 2050 and 2080.

Similarly, mechanical ventilation will experience an increase of almost 3\%, when compared to 2020. Table 4 shows the detailed results for each period under analysis.

Table 4. Expected increase of consumption for mechanical ventilation.

\begin{tabular}{|l|c|c|}
\hline \multicolumn{1}{|c|}{ Intervals } & $\mathbf{2 0 2 0} \rightarrow \mathbf{2 0 5 0}$ & $\mathbf{2 0 5 0} \rightarrow \mathbf{2 0 8 0}$ \\
\hline Ventilation & $+3.87 \%$ & $+2.57 \%$ \\
\hline
\end{tabular}

Finally, an observation on air changes per hour (ACH) has been analysed. Figure 26 shows the overall monthly variation for the years under consideration. As expected, the summer $\mathrm{ACH}$ is higher than winter and there will be little change over the years.

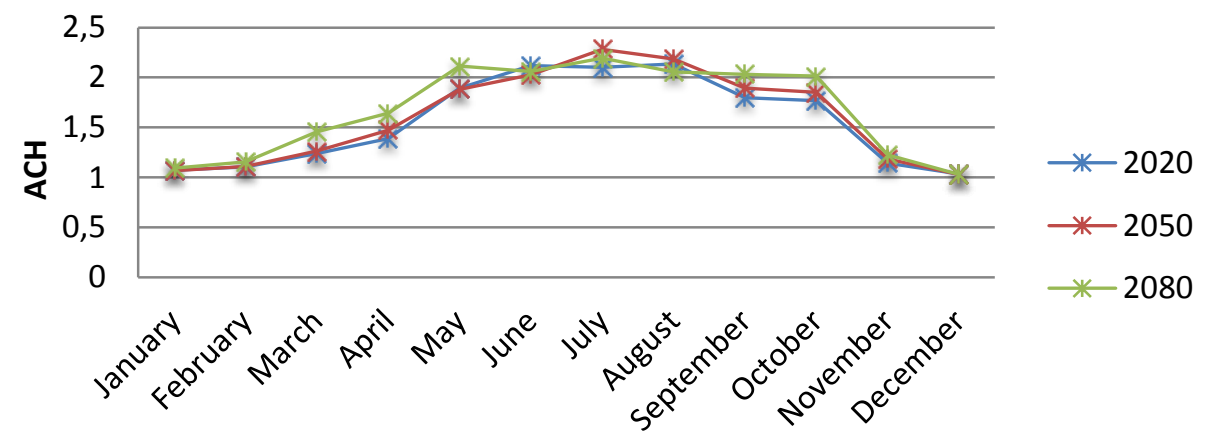

Fig.26. Development of air changes per hour versus the months in 2020, 2050 and 2080.

\section{Conclusions}

In this paper, a description was given for one of the top ZEB projects in the world, according to LEED certification. The objective of study was to analyse the long-term energy performance of the building, when subjected to climate change in 2050 and 2080. 
In order to implement this analysis, a model of the LUCIA building has been simulated using the DesignBuilder version 5 software and EnergyPlus modeling engine, taking the climatic data used in the Spanish standard for buildings and using a climate data change emulator to obtain the building's energy performance over the next 60 years.

Results have shown that while space heating demand is expected to drop, space cooling will increase appreciably. Knowing and taking stock of this decrease in heating consumption and the increase in cooling consumption, it is concluded that the burning of biomass will have to increase by $25 \%$ to provide more energy to the absorption cooling system. This $25 \%$ increase will be provided with the absorption cooling system working at maximum capacity and the chiller as a support system to complement the energy demand, which together will be sufficient to satisfy the demand, provided that they are assisted by proper preventive maintenance for these energy systems.

The peak demand in the years 2020 and 2050 is fully covered by existing energy systems. As mentioned before, the cooling demand for 2080 would be higher and the existing machines will have a deficiency between $9.45 \mathrm{~kW}$ to $47.72 \mathrm{~kW}$ for a few hours in a year. This is acceptable given that the confidence level of satisfying at least $95 \%$ of the hours of cooling will still be achieved according to the Spanish legislation on energy systems in buildings.

Moreover, any solar photovoltaic excess energy that used to supply the nearby buildings will now be consumed within the building. This implies that in spite of the increase in demand, the existing renewable energy systems will still be capable of supplying the extra energy required, especially for cooling. Thus, the building will retain its unique characteristics as a ZEB.

Finally, with these numerical results, one can draw the conclusion of the negative effects of climate change on ZEB with respect to the parameters of energy consumption and its future impact. However, such a study helps us anticipate these effects and propose new improvements in the facilities and energy systems and proceed to better manage and control the building's operation. Therefore, climate change is an important concept in the building sector, which must be taken into account in the design and maintenance of energy systems and for making improvement proposals for reducing building energy consumption.

\section{References.}

[1] O. Edenhofer, K. Seyboth, Intergovernmental Panel on Climate Change (IPCC), in: Encycl. Energy, Nat. Resour. Environ. Econ., Elsevier, 2013: pp. 48-56. doi:10.1016/B978-0-12-3750679.00128-5.

[2] R. Schaeffer, A.S. Szklo, A.F. Pereira de Lucena, B.S. Moreira, C. Borba, L.P. Pupo Nogueira, F.P. Fleming, A. Troccoli, M. Harrison, M.S. Boulahyad, Energy sector vulnerability to climate change: A review, Energy. 38 (2012) 1-12. doi:10.1016/J.ENERGY.2011.11.056.

[3] R.H. Moss, J.A. Edmonds, K.A. Hibbard, M.R. Manning, S.K. Rose, D.P. Vuuren, The next generation of scenarios for climate change research and assessment, Nature, 463. (2010) 747-756.

[4] S.E. Elias, Climate Change and Energy, in: Ref. Modul. Earth Syst. Environ. Sci., Elsevier, 2017. doi:10.1016/B978-0-12-409548-9.10515-9.

[5] G.S. Brager, R.J. de Dear, Thermal adaptation in the built environment: a literature review, Energy Build. 27 (1998) 83-96. doi:10.1016/S0378-7788(97)00053-4.

[6] ASHRAE, ASHRAE Handbook-Fundamentals, ASHRAE Handbook-Fundamentals. (2009). doi:10.1017/CBO9781107415324.004.

[7] R. and A.C.E. American Society of Heating, ANSI/ASHRAE/IES Standard 90. 1-2010 Energy Standard for Buildings Except Low-Rise Residential Buildings, 2010.

[8] M.R. Gaterell, M.E. McEvoy, The impact of climate change uncertainties on the performance of energy efficiency measures applied to dwellings, Energy Build. 37 (2005) 982-995.

doi:10.1016/J.ENBUILD.2004.12.015. 
[9] M. Auffhammer, E.T. Mansur, Measuring climatic impacts on energy consumption: A review of the empirical literature, Energy Econ. 46 (2014) 522-530. doi:10.1016/J.ENECO.2014.04.017.

[10] A. Robert, M. Kummert, Designing net-zero energy buildings for the future climate, not for the past, Build. Environ. 55 (2012) 150-158. doi:10.1016/J.BUILDENV.2011.12.014.

[11] D.H.W. Li, L. Yang, J.C. Lam, Impact of climate change on energy use in the built environment in different climate zones - A review, Energy. 42 (2012) 103-112. doi:10.1016/J.ENERGY.2012.03.044.

[12] J.M. Rey-Hernández, E. Velasco-Gómez, J.F.S. José-Alonso, A. Tejero-González, F.J. ReyMartínez, Energy Analysis at a Near Zero Energy Building. A Case-Study in Spain, Energies2. 11 (18AD) 857. doi:10.3390/en11040857.

[13] DOE EnergyPlus, 2015. (2015). https://energyplus.net.

[14] A. Roetzel, A. Tsangrassoulis, Impact of climate change on comfort and energy performance in offices, Build. Environ. 57 (2012) 349-361. doi:10.1016/J.BUILDENV.2012.06.002.

[15] R.S. Srinivasan, W.W. Braham, D. E.Campbell, C.D. Curcija, Re(De)fining Net Zero Energy: Renewable Emergy Balance in environmental building design, Build. Environ. 47 (2012) 300315. doi:10.1016/J.BUILDENV.2011.07.010.

[16] H. Wang, Q. Chen, Impact of climate change heating and cooling energy use in buildings in the United States, Energy Build. 82 (2014) 428-436. doi:10.1016/j.enbuild.2014.07.034.

[17] J.C. Ciscar, P. Dowling, Integrated assessment of climate impacts and adaptation in the energy sector, Energy Econ. 46 (2014) 531-538. doi:10.1016/J.ENECO.2014.07.003.

[18] Meteonorm, Meteonorm - Global meteorological database, Meteotest. (2012).

[19] CTE (Spanish Technical Building Code), (2013). http://www.codigotecnico.org.

[20] M.F. Jentsch, P.A.B. James, L. Bourikas, A.B.S. Bahaj, Transforming existing weather data for worldwide locations to enable energy and building performance simulation under future climates, Renew. Energy. 55 (2013) 514-524. doi:10.1016/j.renene.2012.12.049.

[21] P. Shen, N. Lior, Vulnerability to climate change impacts of present renewable energy systems designed for achieving net-zero energy buildings, Energy. 114 (2016) 1288-1305. doi:10.1016/J.ENERGY.2016.07.078.

[22] D. Coakley, P. Raftery, M. Keane, A review of methods to match building energy simulation models to measured data, Renew. Sustain. Energy Rev. 37 (2014) 123-141. doi:10.1016/j.rser.2014.05.007.

[23] University of Southampton, Climate Change World Weather File GeneratorCCWorldWeatherGen, (2016). http://www.energy.soton.ac.uk/ccworldweathergen/.

[24] M.F. Jentsch, A.S. Bahaj, P.A.B. James, Climate change future proofing of buildings-Generation and assessment of building simulation weather files, Energy Build. (2008). doi:10.1016/j.enbuild.2008.06.005.

[25] L. Guan, Preparation of future weather data to study the impact of climate change on buildings, Build. Environ. 44 (2009) 793-800. doi:10.1016/J.BUILDENV.2008.05.021.

[26] S.E. Belcher, J.N. Hacker, D.S. Powell, Constructing design weather data for future climates, Build. Serv. Eng. (2005). doi:10.1191/0143624405bt112oa.

[27] H. Kikumoto, R. Ooka, Y. Arima, T. Yamanaka, Study on the future weather data considering the global and local climate change for building energy simulation, Sustain. Cities Soc. 14 (2015) 404-413. doi:10.1016/J.SCS.2014.08.007.

[28] LEED Certification, (2018). https://new.usgbc.org/leed.

[29] Spain Green Building Council (GBC), (2018). http://www.spaingbc.org/web/.

[30] European Environmental Agency (EEA), (2018). https://www.eea.europa.eu/. 
[31] ModBUS protocol, (2018). http://www.modbus.org/.

[32] Digital Addressable Lighting Interface (DALI), (2018). http://www.dali-ag.org/.

[33] SIEMENS, DESiGo, (2018).

http://www.buildingtechnologies.siemens.com/bt/global/en/buildingautomation-hvac/buildingautomation/building-automation-and-control-system-europe-desigo/management-station/desigoweb/pages/desigo-web.aspx.

[34] International Organization for Standardization (ISO), (2018). https://www.iso.org/. 